\title{
Paradigmas de producción urbana y sus resistencias: ciudad, metrópolis y postmetrópolis
}

\author{
Urban production paradigms and their resistances: \\ city, metropolis and postmetropolis
}

JORGE LEÓN CASERO (Universidad de Zaragoza) y JULIA URABAYEN (Universidad de Navarra)

Artículo recibido: 28 de abril de 2019

Solicitud de revisión: 18 de septiembre de 2019

Artículo aceptado: 11 de noviembre de 2019

León Casero, Jorge y Urabayen, Julia (2020). Paradigmas de producción urbana y sus resistencias: ciudad, metrópolis y postmetrópolis. Recerca. Revista de Pensament i Análisi, 25(2), pp. 9-30.

Resumen

Los fenómenos urbanos son modos concretos de reproducción social y, como toda reproducción, tienen un carácter histórico. En este artículo se defenderá que es posible identificar tres grandes paradigmas históricos en el desarrollo urbano del Occidente moderno - la ciudad, la metrópolis y la postmetrópolis- y que su forma de gobernanza coincide con los tres tipos de poder identificados por Foucault: el soberano, el disciplinar y el biopolítico. Además, se analizará cómo cada una de estas tres dobles configuraciones de la reproducción social genera unos puntos neurálgicos, cuya manipulación produce un impacto sobre el sistema mucho mayor que cualquier otra posible acción, tanto si está orientada al dominio institucional del poder constituido como a la resistencia frente al mismo. El presente trabajo aborda la lógica de funcionamiento de estos tres modelos urbanos, identificando sus respectivos centros neurálgicos como punto de partida desde el que es viable constituir el sujeto político antagónico más efectivo posible en cada uno de ellos.

Palabras clave: teoría de la ciudad, urbanismo, resistencia, marxismo, gobernanza.

\section{Abstract}

Urban phenomena are concrete modes of social reproduction and, like all reproduction, they are of a historical nature. This article will explain that it is possible to identify three major historical paradigms in the urban development of the modern West - the city, the metropolis and the postmetropolis - and that its form of governance 
coincides with the three types of power identified by Foucault: sovereign, disciplinary and biopolitical. In addition, it will analyze how each of these three double configurations of social reproduction generate neuralgic points, whose manipulation produces an impact on the system much greater than any other possible action, whether oriented towards the institutional domain of constituted power or to the resistance against it. The present work addresses the logic of these three urban models, identifying their respective neuralgic centers as a starting point from which it is viable to constitute the most effective antagonistic political subject in each of them.

Key Words: Theory of the city, Urbanism, Resistance, Marxism, Governance.

\section{INTRODUCCIÓN}

Desde el punto de vista del operaísmo italiano, el fenómeno urbano debe ser entendido como un modo concreto de reproducción social, lo que implica la producción material - mercancías - e inmaterial — conocimientos- de objetos - economía- y sujetos - biopolítica-. Las formas en las que esos modos de producción se crean y organizan no son unívocas ni eternas. Por ello, el concepto ciudad no tiene un significado único: los modos de reproducción han variado a lo largo de la historia, si bien siempre se ha mantenido una profunda relación entre los fenómenos urbanos y los sociopolíticos.

En este artículo analizamos únicamente los fenómenos urbanos occidentales modernos. En su estudio establecemos tres paradigmas fundamentales de reproducción urbana - ciudad, metrópolis y postmetrópolis- e intentamos mostrar el modo en que su forma de gobierno y producción coincide con los tres modos de poder comentados por Foucault en su curso de 1977-1978 Seguridad, Territorio y Población (Foucault, 2006): el soberano, el disciplinar y el biopolítico.

Además, analizamos cómo cada uno de estos tipos de producción y gobernanza urbana tiene - al menos- dos posibles vertientes de desarrollo. Una que podríamos denominar institucional o «constituida» y otra que podría ser denominada antagónica, de resistencia o «constituyente» (Negri, 1994).

De ahí que cada forma de producción de lo urbano emplee una lógica hegemónica distinta y que, por ello, la eficiencia de los movimientos sociales y políticos que pretendan oponerse o luchar contra dicho régimen dependa de su capacidad para poder utilizar a su favor las lógicas productivas hegemónicas (Negri y Guattari, 1996) en cada uno de los paradigmas.

El estudio de los modelos urbanos de reproducción y los tipos de acciones políticas más efectivas en cada uno, por otra parte, permitirá descartar una 
postura sostenida por gran parte de los arquitectos, urbanistas, sociólogos, geógrafos, antropólogos y filósofos, que utilizan acríticamente un concepto supuestamente universal y homogéneo de ciudad. En nuestra opinión, esa visión únicamente resucita ideales propios de una visión romántica y prerafaelita de la ciudad medieval como comunidad (Sennett, 2018; AA. VV., 2011). Una visión más propia de las utopías decimonónicas de William Morris que de una propuesta plausible de construcción de lo común en las actuales postmetrópolis (Soja, 2008).

La visión medievalista de la ciudad como comunidad jurídicamente autárquica frente a un régimen feudal identificado demasiado rápidamente con la actual globalización (Sassen, 2010) se ha transformado en el ideal de una multitud subjetivamente antagónica, pero objetivamente subsumida en las sociedades tecnológicas.

El problema actual consiste en que el modo de producción y gobernanza de las ciudades se ha transformado completamente en las últimas cuatro décadas, coincidiendo con las innovaciones desarrolladas a partir de la tercera revolución industrial vinculadas al auge de la cibernética y la automatización de los sistemas productivos (Tomás Fornés y Cegarra Dueñas, 2016). Inicialmente, esta automatización fue aplicada preferentemente a los grandes núcleos de producción de valor existentes en las últimas fases del Estado de bienestar -las fábricas-; sin embargo, en las dos últimas décadas se ha producido un incremento progresivo de su aplicación a la gestión del funcionamiento de las ciudades (Shmelev y Shmeleva, 2019).

Las progresivas liberalizaciones, privatizaciones y reestructuraciones jurídicas promovidas por el auge del neoliberalismo han motivado que sean las ciudades - no las fábricas o la Administración pública, como sucedió en los siglos XIX y XX- los núcleos donde se genera la mayor parte del producto interior bruto de un territorio. De ahí que se pueda sostener que «la metrópolis es para la multitud lo que la fábrica era para la clase obrera industrial [...] La metrópolis es una fábrica» (Negri y Hardt, 2011: 256).

Además, el incremento sin paragón de la población urbana derivado de la automatización de las actividades productivas en el campo y la industria ha supuesto un auge hasta ahora inusitado del sector servicios presente en las ciudades, lo que permite sostener que «hoy, una ciudad es en sí misma una fuente de producción» (Negri, 2007: 319). Ello implica que «las ciudades son empresas colaborativas a gran escala» (Harvey, 2007: 221).

Para conceptualizar adecuadamente la lógica de reproducción propia de nuestras actuales postmetrópolis y sus posibles centros neurálgicos de resis- 
tencia, dividiremos el presente artículo en dos secciones. En la primera, expondremos las lógicas productivas y de gobierno de los tres principales modos de poder característicos del fenómeno urbano del Occidente moderno. En la segunda, trataremos de identificar los principales espacios de resistencia efectiva posibilitados por cada una de esas lógicas reproductivas. Por último, en las conclusiones expondremos el modo en que nuestra concepción de la postmetrópolis difiere de la mantenida por algunos de los principales teóricos de la ciudad que se han dedicado al tema (García Vázquez, 2016; Soja, 2008) y lo que ello conlleva para la redefinición del antagonismo social postmetropolitano.

\section{TECNOCRACIAS DEL ESPACIO URBANO}

La práctica totalidad de las utopías y ciudades ideales renacentistas obedecen a modelos que pretenden lograr una ordenación ex nihilo de una multiplicidad de actividades productivas y políticas presentes en el nuevo modo de vida social aparecido unos siglos antes: la ciudad. En las utopías de Moro, Campanella, Andreae y Bacon están algunas de las temáticas que han nutrido la filosofía política en occidente durante más de medio milenio: propiedad privada y colectiva, regulación del trabajo, desarrollo tecnocientífico, educación pública y división de poderes. Es decir, gran parte de los tópicos más comunes que han ocupado los debates de la teoría y la praxis políticas occidentales posteriores fueron previamente concebidos en el marco del pensamiento de la ciudad, vista como el gran mecanismo armonizador susceptible de funcionar automática y eternamente.

Aunque el mecanicismo es un concepto que se vincula normalmente a la filosofía de la naturaleza del siglo XVII, en los siglos XV y XVI surgió un interés inusitado hasta esa fecha por unos mekhanés conceptualizados como ejemplos paradigmáticos de lo que en la actualidad denominaríamos automatización de sistemas. A este respecto, Chastel comenta, a modo de ejemplo, la pasión sentida por Marsilio Ficino en 1475 cuando observó un «artilugio de autómatas» que, según el historiador francés, «le pareció un excelente símbolo del orden cósmico» (Chastel, 1982: 216).

Según Chastel, «toda la época tuvo pasión por los juguetes mecánicos» hasta el punto de que en esos se desarrollaría una auténtica «filosofía de los autómatas» (Chastel, 1982: 216). Al comparar el orden cósmico con esos juguetes mecánicos - vistos ambos como «un mecanismo perfectamente articulado» (Chastel, 1982: 216)_, la filosofía política renacentista desarrolló el con- 
cepto de ciudad como el mecanismo por excelencia para lograr la articulación armónica de las múltiples fuerzas productivas que estaban naciendo en su interior.

El desarrollo de esta articulación fue llevado a cabo por los primeros arquitectos modernos gracias a la utilización de la geometría y la perspectiva en tanto que técnicas paradigmáticas de control y vigilancia del espacio urbano debido a la sistematización del mismo que conllevan (Tafuri, 1995: 35 ).

Sistematización y automatización mecánica serán, pues, las dos fuerzas principales que guiarán las teorías políticas de las ciudades renacentistas. Con el objetivo de legitimar ese proyecto urbano, se empleará una teoría de las proporciones espaciales inspirada en la teoría musical y defendida mediante el recurso a ciertos conceptos propios de la filosofía griega y el derecho romano. Concretamente, el concepto de nomos (vouos) de la tierra - simultáneamente ley, razón como forma lógico-matemática a/b y proporción en tanto forma geométrica o aritmética $\mathrm{a} / \mathrm{b}=\mathrm{c} / \mathrm{d}$ - será utilizado para indicar la racionalidad propia del modo de vida urbano como derecho, reparto, ordenación, proporción o medida, frente a la irracionalidad característica del que salía de los precisos límites de la ciudad ( $\pi \varepsilon ́ \rho a s$ en griego, lira en latín), pues aquel que salía de la ciudad hacia la terrorífica desmesura del territorio (terreo=terror) era precisamente aquel que deliraba.

Es decir, en este planteamiento, tanto espacial como conceptualmente hablando, la condición de posibilidad de lo racional, y por tanto del reparto de lo público, recupera de la Antigüedad greco-romana el proyecto de establecer una medida del espacio físico a través del desarrollo de la geometría y la agrimensura. La cosa pública por excelencia, la ciudad o polis ( $\pi 0 \lambda \iota \varsigma$ ), era entendida como forma más perfecta y acabada de esta medición y racionalización de un territorio común indefinido e inconmensurable, que ya había sido previamente mediado por la agrimensura de los latifundios.

Al reflexionar sobre ese modo de delimitación de lo racional y de lo urbano, Cassirer sostuvo que «el derecho público romano guarda la más estrecha conexión con esta forma de limitación» (Cassirer, 1998: II, 136) de la tierra. Esta conexión se ve con más claridad al añadir que la misma división entre ager publicus y ager divisus et adsignatus, esto es, entre terrenos comunes y propiedad, dependía directamente de la posibilidad de delimitar y medir de forma precisa esta última. Únicamente aquella tierra medida y cercada de forma precisa «por líneas matemáticas e invariables» (Cassirer, 1998: II, 136) podía ser considerada, primero, espacio sagrado y, posteriormente, propiedad privada. 
Una vez establecidos estos límites netos entre el interior y el exterior, se comprende fácilmente cómo todo elemento extranjero que pretenda establecer una relación con la polis en tanto que construcción autónoma de lo público únicamente podrá hacerlo según una relación polémica ( $\pi 0 \lambda \varepsilon ́ \mu \circ)$ y violenta, ya que sería irracional y desmedida. Derecho (nomos) y técnica (agrimensura) como ordenación del espacio son, pues, las condiciones de posibilidad de la polis y las que definirán la eficiencia de la resistencia en la misma.

Ahora bien, la ordenación socioespacial puede hacerse de diversas maneras. La ciudad renacentista la realizó, siguiendo al mundo clásico, por medio de la geometría y la agrimensura. La metrópolis decimonónica, en cambio, lo hizo a través de la economía. De ahí que Argan afirme que «si los urbanistas clásicos tenían un concepto geométrico del espacio, los urbanistas modernos tienen un concepto económico» (Argan, 1969: 76).

Cuando el espacio geométrico deja de ser la medida del cosmos, el tipo de política vinculada a la polis cede su lugar a la economía política como nuevo saber del Estado - propiamente hablando, estadístico- con el que se regula el desarrollo del espacio público. Allí donde la ciudad renacentista decía geometría (forma), la moderna metrópolis dirá aritmética (número), álgebra, contabilidad y cuantificación del valor.

El dibujo como técnica propia del arquitecto renacentista quedará reducido a simple valor estético - susceptible de reconvertirse en valor económico-, mientras que el control y la planificación de la metrópolis pasará a depender de un nuevo perfil profesional: el del urbanista. Economía, geografía e ingeniería de caminos serán parte ineludible de la nueva ciencia del Estado necesaria para disciplinar un espacio urbano cada vez más fluido, aunque siempre al servicio de la especulación inmobiliaria impuesta por un nuevo modo de reproducción basado en el libre mercado del suelo.

Es cierto que con anterioridad al siglo XIX existía un mercado de la vivienda. Sin embargo, el inicio de las obras no comenzaba hasta que el cliente había reunido el dinero necesario para su financiación. En cambio, a comienzos del siglo XIX el modo de producción y financiación del espacio urbano se transforma profundamente. Un testimonio de esa transformación puede verse en el famoso extracto del Report from the Select Committee on Bank Acts de 1857 comentado por Marx. En ese documento, un encargado del sector de la edificación expone a los miembros del comité el funcionamiento del nuevo modo producción: 
En su juventud, nos dice, la mayoría de las casas se construían por encargo y el importe le era abonado al contratista al llegar a ciertas fases de la construcción. Se edificaba muy poco para la especulación [...] Desde hace cuarenta años, todo esto ha cambiado. Ahora, se construye muy poco por encargo. El que necesita una nueva casa la busca entre las construidas para especular con ellas o entre las que se hallan en construcción. El empresario de construcciones ya no trabaja para sus clientes, sino para el mercado; se halla obligado, lo mismo que cualquier otro industrial, a tener en el mercado sus mercancías terminadas. Mientras que antes un contratista solía emprender al mismo tiempo, cuando más, la construcción de tres o cuatro casas para la especulación, ahora tiene que comprar grandes solares, construir en ellos hasta cien o doscientas casas y aventurarse así en una empresa que rebasa veinte y hasta cincuenta veces su capital. Los fondos necesarios se movilizan mediante hipotecas y el dinero se va poniendo a disposición del empresario a medida que se desarrolla la construcción de las distintas casas. En estas condiciones, si se produce una crisis que paraliza el pago de las cantidades abonadas a cuenta, se viene a tierra por lo general toda la empresa (citado en Marx, 1999: II, 207-208).

Al contrario de lo que se afirma habitualmente, esta concepción económica del espacio urbano no se opone a una estricta normalización y uniformización estatal del mismo, sino que, juntas, conforman un único tipo de gobernanza identificado por Foucault como el dispositivo disciplinar (Foucault, 2005). Mientras que el proyecto utópico de la ciudad renacentista pretendía ordenar y segmentar el espacio a partir de un único proyecto geométrico de urbanización producido por un poder soberano, el funcionamiento del libre mercado presente en la producción de la metrópolis dará lugar a una segregación espacial de la población que establecerá una relación directamente proporcional entre nivel de renta y cercanía al centro. De este modo, comenzará el éxodo metropolitano de las clases trabajadoras a unos suburbios donde la relación entre lo racional - urbano- y lo irracional — territorio- no se distingue con claridad.

La metrópolis no necesita proyectos geométrico-formales para la delimitación del espacio urbano. El mercado ya pone a cada persona en su lugar. En este modelo de poder, la función de la Administración pública se reducirá a mantener el orden y suministrar los recursos necesarios para el nuevo modo de producción vigente.

Para ello desarrollará una doble estrategia. En primer lugar, generará una progresiva «arquitecturación» (Foucault, 2006: 36) del espacio público que permite la vigilancia del espacio y el control de las principales vías de tráfico por parte de las fuerzas del orden, lo que es clave, pues en la metrópolis «la calle es el tráfico» (Virilio, 2006: 37) y, al menos en lengua francesa, 
el nombre canalla [voyous] tiene una relación especial con la vista [vue], la red vial [voirie] urbana, la red vial de la ciudad o de la polis, y, por tanto, con la calle [pues] el desvelamiento del canalla consiste en hacer un mal uso de la calle (Derrida, 2003: 97).

En segundo lugar, dotará de toda una batería de equipamientos públicos, como cárceles, hospitales, colegios y tribunales, a los distintos distritos administrativos en los que se divide la metrópolis. Allí donde el mercado segrega la población y polariza el espacio urbano mediante la dualidad centro-periferia, la nueva técnica urbanística desarrollada por las Administraciones públicas controla el flujo de personas y mercancías generado por esta bipolaridad con el objetivo de mantener en sus suburbios a una mano de obra apta para la producción fabril de las mercancías destinadas a ser consumidas por los habitantes del centro.

Aunque puede parecer que este modo de reproducción social sigue plenamente vigente actualmente, la crisis financiera e inmobiliaria del 2007 ha sacado a la luz una profunda reorganización del modo de producción del espacio urbano que se habría estado fraguando durante las últimas cuatro décadas y que ha llevado a gran parte de los teóricos de las ciencias urbanas y sociales a hablar de postmetrópolis. De forma general, las «postmetrópolis» (Soja, 2008), «territorios» (Brenner, 2013) o «metápolis» (García Vázquez, 2016) son aquellas ciudades en las que los desarrollos de la cibernética y la automatización de los sistemas productivos han eliminado cualquier posibilidad de controlar los flujos de valor mediante técnicas espaciales o urbanísticas. En ellas, la arquitectura como técnica de control y medición del espacio de flujos (Castells, 1997) cede su lugar a la arquitectura de sistemas, lo que supone una subordinación de la soberanía territorial al control de una información globalizada.

En un mundo en el que es imposible aislar o controlar cualquier espacio del flujo de información internacional que los atraviesa, dejan de ser hegemónicas las técnicas disciplinarias descritas por Foucault, que comienzan a funcionar ordenadas según el régimen biopolítico propio de las postmetrópolis, pues la hegemonía del régimen disciplinar siempre estuvo ligada a un fuerte control del espacio y el territorio. Así pues, como previó el jurista Ernst Forsthoff, en las actuales postmetrópolis «el Derecho capitula ante la técnica» (Forsthoff, 1966: 50).

Actualmente existen dos grandes líneas no excluyentes que pretenden explicar los nuevos desarrollos urbanos que han comenzado a encauzar este nuevo modo de producción del espacio urbano: las smart cities y los procesos de regeneración urbana. En el primer caso, la estrategia principal consiste en co- 
nectar a la nube todas las infraestructuras, edificaciones (públicas y privadas) y servicios de la ciudad con la intención de desarrollar un campo de datos que permita una reorganización continua a tiempo real de los recursos, siempre móviles. El objetivo es lograr una mayor racionalización y optimización del tráfico de flujos materiales, mercantiles, económicos y de información.

Mientras que la metrópolis decimonónica fue controlada a partir de infraestructuras y equipamientos públicos, las nuevas smart cities han inundado el espacio urbano de sensores de todo tipo que dan información relativa a la contaminación del aire, la densidad del tráfico peatonal y rodado, el nivel de radiación, las condiciones higrotérmicas, el riesgo sísmico y de incendios, el estado del asfalto o la contaminación acústica y lumínica, entre muchos otros ámbitos. Por su parte, la población - y ya no el individuo- es construida como objeto de estudio y gestión biopolítica (Foucault, 2004) a partir de una nueva matriz de datos de tipo estadístico clasificados en función de la edad, el género, la profesión o el lugar y las condiciones físicas de residencia.

La metrópolis trataba de disciplinar a todo individuo según una norma $o$ pauta de funcionamiento único. La postmetrópolis, en cambio, gestiona datos para evitar bruscas variaciones en la depreciación o inflación de la valorización tanto de sus recursos - humanos y materiales - como de sus productos. Expresado con una analogía médica de resonancias claramente foucaultianas, podríamos decir que, mientras que la disciplina metropolitana se construía a imagen de un individuo sano, la biopolítica de la postmetrópolis es un simple control de los principales factores epidemiológicos. En el primer caso, el tratamiento o medida de seguridad es la cuarentena en tanto que expulsión del espacio social hegemónico - el centro- hacia las periferias: modelo de la peste. En el segundo, la medida de seguridad o terapia es la vacunación, dispositivo característico del tratamiento de la viruela. Es precisamente en la vacunación donde entra en funcionamiento la lógica propia de las actuaciones de regeneración y rehabilitación urbana características de la postmetrópolis, descrita por Mark Davis precisamente como «Zeitgeist de la reestructuración urbana» (citado en Soja, 2008: 423).

Aunque existen algunos precedentes en el mundo anglosajón que fueron realizados en las décadas de los sesenta y setenta (Goodman, 1972), el inicio de las actuaciones de regeneración urbana en la Unión Europea puede fecharse en los programas Urban I (1994-1999) y Urban II (2000-2006), que actualmente están siendo continuados por las Estrategias de Desarrollo Urbano Sostenible Integrado o EDUSI. Todos estos programas enfatizan el enfoque area based desarrollado en el informe de la OCDE Integrating Distressed Urban Areas (1998). 
Según este planteamiento, las ayudas económicas destinadas a paliar las desigualdades sociales debían dejar de asignarse únicamente en función de las condiciones de la población y tendrían que tomar en consideración un conjunto de datos relativos a la población y a las condiciones del espacio urbano.

El argumento utilizado por la OCDE destacaba la mayor eficacia de los resultados obtenidos en aquellos proyectos en los que las ayudas sociales se habían coaligado con intervenciones orientadas a la regeneración del patrimonio arquitectónico y las infraestructuras urbanas.

Sin embargo, los resultados obtenidos en los últimos veinte años han mostrado un incremento de los procesos de gentrificación urbana, lo que debe ser interpretado en el sentido que adquiere en una lógica postmetropolitana. A diferencia del régimen de producción metropolitano, el principal objeto de especulación de estos nuevos procesos de gentrificación ya no son solares perfectamente delimitados geométrica y económicamente, sino el espacio urbano en su conjunto. Es decir, tanto el espacio físico medido en superficie (geometría) y dinero (economía), como el conjunto de relaciones sociales y económicas que promueven un cierto tipo de vida (biopolítica).

Aunque la población continúa polarizándose según el nivel de renta, ello no significa ya una polarización entendida como dualidad espacial a nivel urbano. Este nuevo modo de automatización e intervención sobre el espacio urbano implica la proliferación de una red de diferenciaciones territorialmente dispersas que se distancia de la idea de ciudad-dual presentada por Wacquant (2007) o Secchi (2013). Pues, tal y como afirma Rem Koolhaas (2007), el espacio - basura- generado por la postmetrópolis es fractal, no dual.

\section{ESPACIOS DE RESISTENCIA URBANA}

Una vez expuestos los paradigmas de producción urbana —ciudad, metrópolis y postmetrópolis-, así como sus diferencias a la hora de generar la reproducción social, se pueden establecer dos tesis fundamentales para comprender la resistencia urbana posible en cada uno de ellos. En primer lugar, cada modo de reproducción del espacio urbano genera unos puntos neurálgicos, cuya gestión implica un impacto sobre el sistema en su conjunto, que es mucho mayor que cualquier tipo de acción o resistencia realizada sobre o a partir de otros puntos del mismo.

En segundo lugar, la posibilidad de realizar de forma eficiente acciones sobre esos puntos neurálgicos depende de un determinado tipo de sujeto y 
organización política que coincide, normalmente, con un modo de vida cotidiano susceptible de generar por sí mismo ciertos espacios efectivos de resistencia o antagonismo. Es decir, no toda acción antagónica es igualmente efectiva y la eficacia de la resistencia ejercida frente a un determinado sistema de reproducción depende de la propia lógica de funcionamiento de dicho sistema (Negri y Guattari, 1996; Negri, 2004; Zibechi, 2012, 2007).

Comenzaremos el análisis con el primer paradigma. En la ciudad renacentista, el sujeto antagonista hegemónico y los espacios de resistencia generados por él son anteriores a la implantación del proyecto utópico-soberano. Como diría Negri, la lucha o resistencia también en este caso es ontológica y cronológicamente previa al proyecto institucional que trata de dominarla. El modelo paradigmático de resistencia todavía presente en la ciudad renacentista fue el desarrollado por el popolo propio de las ciudades tardomedievales, entendido como una «asociación fraternal o hermandad» (Weber, 1987: 43).

La importancia creciente que adquirieron las ciudades medievales como grandes centros de producción de valor motivó que se trasladase a ellas una incipiente burguesía de propietarios individuales. En esas ciudades, la práctica totalidad de poderes fácticos de la época obtuvo una representación social, económica y, ante todo, jurídica, pues cada uno de esos poderes disponía de una jurisdicción propia con la que se autorregulaba.

En ese período se pueden identificar cinco grandes tipos de poderes con su consiguiente jurisdicción o derecho propio: los poderes episcopales (derecho canónico), los poderes administrativos de los vizcondes (derecho administrativo), los poderes de los grandes propietarios y comerciantes (lex mercatoria), los poderes de las uniones profesionales de las clases trabajadoras urbanas (gremios) y, finalmente, los poderes de las autoridades judiciales, que a su vez se dividían en cuatro jurisdicciones o tipos de derechos personales - no territoriales-distintos: el derecho de la corte, el derecho feudal, el derecho común o de gentes y el derecho eclesiástico.

Junto a esos poderes fáctico-jurídicos, surgió uno de naturaleza esencialmente política: el popolo de las ciudades medievales del norte de Italia - también denominado societas, credenza, mercadanza o communanza-, que era una organización específicamente urbana que reunió a todos aquellos habitantes de la ciudad que no pertenecían a ninguno de los poderes fácticos precedentes con el objetivo de lograr la representación y la defensa de sus intereses. El popolo llegó a constituir una organización autónoma con sus propios funcionarios, sus finanzas y su organización militar. Por ello, Weber no dudó en 
calificarla como la «primera asociación política totalmente consciente de su carácter ilegítimo y revolucionario» (Weber, 1987: 118).

Desde esta óptica, el ideal utópico de proyectar ex nihilo una ciudad completamente armónica y jerarquizada según un único arché o centro neurálgico de poder con una única jurisdicción común para todos los individuos, además de ser un proyecto de unificación de las distintas fuerzas en pugna, debería ser leído como un proyecto concreto de neutralización de la incipiente autodeterminación del popolo (Tafuri, 1995).

Frente al ideal del buon governo y la división comunitaria — no jerárquica- del espacio urbano según los tipos de poderes existentes en la ciudad, el proyecto utópico renacentista pretendía imponer la unidad racional de la forma urbis geométrica, entendida como la técnica paradigmática capaz de generar un control unitario sobre el conjunto de la ciudad. Según Manfredo Tafuri (1995), los ejemplos más representativos del carácter altamente pragmático de los ideales utópicos son dos. El primero es el proyecto de Julio II para la renovación de la Via Giulia entre 1503 y 1513, centrado en torno a la construcción de un palazzo dei tribunali proyectado por Bramante que pretendía unificar bajo un solo derecho todos los poderes fácticos y jurídicos presentes en Roma. El segundo es el proyecto de León X desarrollado entre 1513 y 1521 para la construcción de un palazzo mediceo proyectado por Antonio da Sangallo junto a una Piazza navona conectada directamente con la Piazza del popolo.

En segundo lugar, analizaremos los espacios de resistencia efectivos propios de la metrópolis. En nuestra opinión, el gran problema que atravesó todo el siglo XIX, la mayor parte del XX y sigue estando presente en la actualidad fue la idealización del popolo y de toda comuna medieval vista desde el ideal socialista de una fraternidad de artesanos opuesta a una propiedad privada de tipo industrial, precisamente en un momento en que la lógica de reproducción sociopolítica del espacio urbano había mutado completamente. A este respecto, el propio Marx avisaba ya de que el fallo fundamental de su época consistía en que

esta nueva Comuna [la Comuna de París de 1871], que viene a destruir el poder estatal moderno, se ha confundido con una reproducción de las comunas medievales [hasta el punto de que] el antagonismo entre la Comuna y el poder del Estado se ha presentado equivocadamente como una forma exagerada de la vieja lucha contra el excesivo centralismo (Marx, 2013: 38). 
Un centralismo que era el rasgo propio de la ciudad utópica. Ahora bien, tal y como hemos expuesto en el apartado anterior, el punto neurálgico de la reproducción metropolitana no era el centralismo soberano de la ciudad utópica, sino la segregación espacial de la población producida por el mercado. De ahí que cualquier proyecto o espacio de resistencia que oriente su acción a luchar única o principalmente contra el centralismo jurídico-político de la Administración pública estuviera condenado al fracaso en este modo de reproducción social.

Lo característico de la Comuna de París, según Marx, no fue el proyecto de fraccionar el poder político en una federación de pequeños estados. La Comuna tenía autonomía local, cierto, «pero ya no como contrapeso a un poder estatal» (Marx, 2013: 39). Lo fundamental para Marx es que, en una época de dualidad antagónica trabajo-capital,

la Comuna era, esencialmente, un gobierno de la clase obrera [...] la forma política al fin descubierta para llevar a cabo dentro de ella la emancipación económica del trabajo. Sin esta última condición, el régimen comunal habría sido una imposibilidad y una impostura (Marx, 2013: 40).

La Comuna es vista, por tanto, como una palanca para extirpar los cimientos económicos sobre los que se construye la dualidad del régimen metropolitano, no como el ideal de una autonomía federativa frente a un proyecto de armonía jerárquica. El objetivo era transformar los principales medios de producción de la época - la tierra, el capital, etc.- en «simples instrumentos de trabajo libre y asociado» (Marx, 2013: 41), no crear una asociación política para la representación o la autodeterminación de los intereses de los individuos excluidos del resto de poderes urbanos.

Por esa razón, los principales decretos adoptados por la Comuna - la supresión del ejército permanente en favor del pueblo armado, el sufragio universal para la elección y revocación de los consejeros municipales o el mandato imperativo sobre los mismos- son entendidos por Marx como algo que está más allá de una simple organización de tipo estrictamente jurisdiccional, pues la Comuna «no había de ser un organismo parlamentario, sino una corporación de trabajo, ejecutiva y legislativa al mismo tiempo» (Marx, 2013: 35) capaz de poner a trabajar en su propio beneficio a todos los equipamientos e infraestructuras públicas anteriormente utilizados por el poder fáctico del capital para normalizar y disciplinar la fuerza de trabajo. 
Aunque la exigencia de autonomía política o autodeterminación espacial fue una cuestión que compartieron las comunas medievales con la Comuna de París, no por ello deberíamos concluir que hay una identidad sustancial entre ambos proyectos de antagonismo urbano. Tanto la lógica de reproducción urbana desde la que actuaban como las fuerzas fácticas a las que se enfrentaban eran radicalmente diferentes. El acto de construir un muro de hormigón armado puede ser el mismo con independencia de qué sea lo que se esté construyendo, pero la eficacia sistémica que ese acto adquiere dentro del proyecto de construcción de un dique de contención es radicalmente diferente de la que tiene dentro del proyecto de construcción de una central hidroeléctrica.

Por último, expondremos lo que creemos que son las principales líneas de un antagonismo social efectivo en las actuales postmetrópolis. En este caso, es importante comprender que la hegemonía urbana de la tradicional dualidad capital-trabajo o centro-periferia ha llegado definitivamente a su fin, sin que por ello dejen de producirse espacios de exclusión social y vulnerabilidad urbana. Cuando se agota la posibilidad de controlar la fuerza de trabajo por medio de la disciplina y la normalización socioeconómica del espacio urbano, se vuelve ineficiente también todo proyecto antagónico consistente en el mero control de clase de unos equipamientos e infraestructuras urbanas diseñadas precisamente desde esa óptica.

Es más, el simple proyecto de creación de una nueva Comuna de París mediante el control de las calles y los barrios a través de la acción vecinal no solo ha dejado de ser eficiente, sino que, de hecho, trabaja a favor de un poder establecido que funciona según la lógica postmetropolitana propia del control epidemiológico. A este respecto, el urbanismo participativo promovido desde las Administraciones públicas es un simple engranaje más dentro de una campaña europea de vacunación por gentrificación en la que toda posible acción espacial ha sido subsumida dentro de la lógica postmetropolitana de un capitalismo de plataforma (Williams, 2015; Srnicek, 2018) altamente condicionado por la tecnología cibernética.

Ahora bien, un sujeto político sin territorio físico como medio en el que desarrollar las relaciones sociales de cotidianeidad que se encuentran en la base de los procesos de subjetivación política (Lefebvre, 1971, 2013) no puede funcionar de forma efectiva ni como popolo, ni como nación, ni como una clase unificada por la segregación espacial. En su lugar, y a pesar de que algunos teóricos puedan considerarlo «débil» (Žižek, 2006; Laclau, 2008), nosotros creemos que el único tipo de sujeto político con vocación antagonista capaz de superar la crisis del espacio urbano como medio de subjetivación política son 
las multitudes teorizadas por Negri en su capacidad para generar agenciamientos maquínicos (Deleuze y Guattari, 2004; Negri y Hardt, 2019: 157-178). $\mathrm{O}$, lo que es lo mismo, son el único sujeto político capaz de configurarse a partir del establecimiento de agenciamientos informacionales en red (Toret et al., 2015).

En un mundo en el que toda la producción está indistinguiblemente socializada a través de un general intellect de escala mundial - hasta el punto de que es imposible determinar el valor aportado por cada individuo a unos productos esencialmente intersubjetivos basados en un lenguaje completamente independizado por primera vez en la historia de los límites territoriales necesarios para su transmisión en tiempo real一,

lo común [solamente puede ser definido como] la red, la serie de bienes materiales [e inmateriales] que permiten reproducirnos y producirnos, movernos y/o hacernos trasportar de un lado a otro de la ciudad (Negri, 2007: 113).

En este punto hay que recordar que, del mismo modo que el proyecto de asociación y autonomía política propio del popolo medieval seguía siendo una condición necesaria, pero ya no suficiente, para el proyecto económico de la Comuna metropolitana, en el presente caso la autonomía biopolítica entendida como autogestión y autodeterminación reproductiva del trabajo continúa siendo condición necesaria, pero no suficiente, para el desarrollo de este nuevo proyecto no territorializado de común. Dentro de un capitalismo de plataforma, el nodo de resistencia fundamental pasa a ser la lucha por un acceso libre a los recursos materiales e inmateriales por garantizar el común, de modo que

la cooperación productiva en el ámbito biopolítico tienda a ser creada en redes sociales entre productores sin necesidad de supervisión y orientación burocráticas (Negri y Hardt, 2011: 100).

Dado que en el régimen biopolítico de reproducción postmetropolitana es la vida cotidiana de la sociedad - y ya no las fábricas - la que pasa a funcionar como forma hegemónica de producción de valor en tanto que productora de información, el espacio urbano comienza a revalorizarse de un modo completamente diferente de como lo hacía en la metrópolis decimonónica. Es por ello que Negri y Hardt consideran las actuales postmetrópolis como 
un depósito y un repertorio de habilidades en el terreno de los afectos, las relaciones sociales, las costumbres, los deseos, los conocimientos y los circuitos culturales (Negri y Hardt, 2011: 255).

Teniendo en cuenta estos aspectos de la reproducción social de las postmetrópolis, se puede ver que su carácter no es dual, sino fractal (García Vázquez, 2016; Soja, 2008). El actual crecimiento de las redes de cooperación y comunicación desarrolladas por la postmetrópolis ha armado a la multitud con nuevas herramientas capaces de superar los antiguos aparatos de segmentación y segregación típicamente disciplinares, si bien es cierto que aún continúan presentes. Ahora bien, al menos para Negri, cuanto mayor es el despliegue de comunicaciones inmateriales desarrollado por la postmetrópolis para automatizar la producción, mayor es la capacidad de la multitud para establecer conexiones, encuentros o agenciamientos de resistencia, postura esta que en los últimos años ha sido criticada por varios autores (Žižek, 20o6; Laclau, 2008; Laval y Dardot, 2015).

Desde nuestro punto de vista, una de las principales debilidades de dichas críticas consiste en que, al haber sido realizadas desde posturas fuertemente sociosimbólicas - especialmente en lo referente a las críticas de Laclau y Žižek-, reducen la concepción de la cibernética a internet y las redes sociales. Ahora bien, si queremos poder precisar adecuadamente el modo de reproducción postmetropolitano, debemos especificar claramente que la cibernética no es internet. Internet es un epifenómeno, mínimo, de la cibernética. Por su parte, esta última consiste en la red de comunicaciones (conexiones y señales) que funciona como infraestructura básica en la organización y automatización de la producción del espacio urbano tanto subjetivamente (redes sociales) como objetivamente (smart cities).

En una lógica productiva que no diferencia ya entre subjetivo (datos relativos a la población) y objetivo (datos relativos a las infraestructuras de producción, transporte y comunicación), reducir la cibernética a los procesos de subjetivación simbólica propios de internet y las redes sociales significaría que no hemos visto el verdadero potencial de la misma. En cambio, captar este rasgo permite entender la razón por la cual la lucha por su control y dominio reviste un carácter estratégico.

Si en el siglo XIX se tomaban las calles de las ciudades, ello se debía a que entonces era una acción de resistencia efectiva en la medida en que dicha acción era capaz de colapsar los sistemas de transporte e intercambio de mercancías utilizados por la clase burguesa. En la actualidad, en cambio, una parte 
cada vez mayor de los intercambios de valor se realiza por las autopistas cibernéticas de la información. De ahí que tomar únicamente las calles comience a ser una acción mucho menos eficiente de lo que lo fue en el siglo XIX.

\section{CONCLUSIONES}

La clasificación de los paradigmas de desarrollo urbano es una cuestión que ha sido ampliamente debatida en la práctica totalidad de disciplinas que confluyen en los estudios urbanos. La práctica totalidad de las mismas considera que, en las últimas cuatro décadas, ha surgido un nuevo paradigma. Desde la arquitectura y el urbanismo (García Vázquez, 2016; Koolhaas, Boeri, Kwinter y Olbrist, 200o; Fernández-Alba, 1998) lo denominaron metápolis. Desde la geografía, postmetrópolis (Soja, 2008) y algunos sociólogos se refirieron a él como ciudad informacional (Castells, 1995) o ciudad-global (Sassen, 200o).

El punto común a todas estas denominaciones es que, con independencia del nivel de determinación que le otorguen, utilizan un criterio de clasificación basado en la preeminencia de la economía - o la economía políticacomo relación sociosimbólica básica.

Concretamente, García Vázquez diferencia entre metrópolis (1882-1939), megalópolis (1939-1979) y metápolis (1979-2007) en tanto que «tres fases relacionadas con sendos cambios del paradigma intelectual motivados por transformaciones del sistema económico» (García Vázquez, 2016: 8).

Del mismo modo, la clasificación de Soja amplía el ámbito cronológico y establece una división entre tres grandes revoluciones urbanas: la primera, del 11 ooo a. de C. al 5000 a. de C., estaría caracterizada por un desarrollo del comercio anterior a la agricultura; la segunda, del 5000 a. de C. al siglo XVIII, lo haría mediante el desarrollo de la agricultura y la ciudad-estado, y la tercera, desde el siglo XVIII hasta la actualidad, quedaría definida por el capitalismo. Bajo este marco general, Soja especifica cinco fases de reestructuraciones capitalistas (1870-1900, 1900-1920, 1920-1940, 1940-1970 y 1970 en adelante), planteando la pregunta de si la última de ellas debería se clasificada como otra fase más o si nos encontramos en el inicio de una cuarta revolución urbana.

El punto fundamental aquí es que, si bien García Vázquez había concebido la primacía de lo económico como propio de las transformaciones urbanas desarrolladas a partir de la metrópolis moderna, la postura de Soja, en cambio, lo convierte en algo propio de cualquier tipo de fenómeno urbano. Postura 
esta que, aun a pesar del mayor peso otorgado al ámbito tecnológico, permanece en las perspectivas mantenidas por Castells y Sassen.

Lo que nuestro artículo propone es un nuevo criterio de clasificación de los fenómenos urbanos. Reconocemos que la economía política es la disciplina adecuada con la que concebir la lógica hegemónica de reproducción social propia de la metrópolis moderna, pero mantenemos que no es capaz de explicar las cuestiones fundamentales que caracterizan otras lógicas urbanas de reproducción social. Por esta razón, creemos que las lógicas de reproducción urbana deberían conceptualizarse en función de las técnicas o las disciplinas hegemónicas desde las que se intentan gobernar los fenómenos espaciales en cada momento: la geometría en la ciudad soberana, la economía política en la metrópolis disciplinar y la cibernética en la postmetrópolis biopolítica.

El núcleo específico o diferenciador de las postmetrópolis no tiene que ver directamente con un nuevo modo de funcionamiento de la economía. Consideramos que sus causas últimas yacen en un cambio de la técnica hegemónica de producción que, efectivamente, conlleva grandes cambios para el funcionamiento de las relaciones económicas. Del mismo modo, si bien reconocemos que existen múltiples modalidades de fenómenos urbanos regidos por la hegemonía de distintas formas de economía - capitalista, socialista, etc.-, reservamos el término metrópolis para todos ellos, incluyendo tanto a las metrópolis decimonónicas del laissez-faire como a las megalópolis planificadas del siglo XX. Por cuestiones de orden cronológico, en este artículo hemos tratado únicamente las primeras.

Una vez en este punto, es importante remarcar la idea de que cada nuevo paradigma de producción urbana —ciudad, metrópolis y postmetrópolis- no niega al anterior, sino que lo incluye dentro de un nuevo marco hegemónico que modifica tanto su funcionamiento sistémico como sus repercusiones globales en el mismo. Así, la geometría sigue siendo utilizada en la metrópolis como técnica de medición del suelo del mismo modo que el valor económico sigue siendo utilizado en la postmetrópolis como técnica de medición del valor del espacio urbano. A su vez, al igual que la geometría no dicta el funcionamiento del sistema de producción metropolitano - y esta es nuestra tesis principal-, la economía ha dejado de dictar las reglas de los principales procesos de generación de valor de las postmetrópolis, que han pasado a ser definidos por una lógica de plataforma que no respeta el fundamento principal de la disciplina económica clásica: la teoría del valor marginal.

En palabras del doctor en economía e ingeniería Klaus Schwab, fundador y director general del Foro Económico Mundial, estamos ante una nueva tec- 
nología de producción en la que «el costo marginal de producir cada producto, bien o servicio adicional tiende a cero» (Schwab, 2016: 37), lo cual «nos obliga a reescribir nuestros manuales de economía» (Schwab, 2016: 53).

En contra de la denominación de Castells, nosotros creemos que no estamos simplemente ante una sociedad de la información -o informacional-, sino ante una sociedad cibernética —es decir, técnica- que no puede ser reducida a redes de comunicación sociosimbólica. Esto nos obliga a replantear el antagonismo social no simplemente desde el trabajo inmaterial, sino desde un proyecto de apropiación de las tecnologías de plataforma.

\section{BIBLIOGRAFÍA}

AA. VV. (2011). Carta de los Comunes. Para el cuidado y disfrute de lo que de todos es. Madrid: Traficantes de sueños.

Argan, Giulio Carlo (1969). Proyecto y destino. Caracas: Universidad Central de Venezuela.

Brenner, Neil (2013). Implosions/Explosions: Towards a study of planetary urbanization. Berlin: Jovis Verlag GmbH.

Castells, Manuel (1995). La ciudad informacional. Madrid: Alianza.

Castells, Manuel (1997). La era de la información. Vol. I. La sociedad red. Madrid: Alianza.

Cassirer, Ernst (1998). Filosofía de las formas simbólicas. Vol. II. México, D.F.: Fondo de cultura económica.

Chastel, André (1982). Arte y humanismo en Florencia en la época de Lorenzo el Magnífico. Madrid: Cátedra.

Deleuze, Gilles y Guattari, Félix (2004). Mil Mesetas. Capitalismo y esquizofrenia. Valencia: Pre-Textos.

Derrida, Jacques (2003). Voyous. Deux essais sur la raison. Paris: Éditions Galilée.

Fernández-Alba, Antonio (1998). Metápolis: La ciudad virtual. Astrágalo, $9,5-8$.

Forsthoff, Ernst (1966). Problemas actuales del Estado social de Derecho en Alemania. Madrid: Publicaciones del Centro de Formación y Perfeccionamiento de Funcionarios. 
Foucault, Michel (2004). Nacimiento de la biopolítica. Curso en el Collége de France (1978-1979). México: Fondo de Cultura Económica.

Foucault, Michel (2005). Vigilar y castigar. Nacimiento de la prisión. Madrid: Siglo XXI.

Foucault, Michel (2006). Seguridad, territorio y población: Curso en el College de France (1977-1978). Buenos Aires: Fondo de Cultura Económica de Argentina.

García Vázquez, Carlos (2016). Teorías e Historia de la ciudad contemporánea. Barcelona: Gustavo Gili.

Goodman, Robert (1972). After the Planners. London: Penguin Books.

Harvey, David (2007). Espacios del capital: hacia una geografía crítica. Madrid: Akal.

Koolhaas, Rem (2007). Espacio Basura. Barcelona: Gustavo Gili.

Koolhaas, Rem, Boeri, Stefano, Kwinter, Stanford y Olbrist, Hans U. (2000). Mutaciones. Barcelona: Actar.

Laclau, Ernesto (2008). Debates y Combates. Buenos Aires: Fondo de Cultura Económica.

Laval, Christian y Dardot, Pierre (2015). Común. Ensayo sobre la Revolución en el siglo XXI. Barcelona: Gedisa.

Lefebvre, Henri (1971). De lo rural a lo urbano. Barcelona: Península.

Lefebvre, Henri (2013). La producción del espacio. Madrid: Capitán Swing. Marx, Karl (1999). El capital. Vol. II. Crítica de la Economía Política. México D.F.: Fondo de Cultura Económica.

Marx, Karl (2013). Manifiesto del Consejo General de la Asociación Internacional de los Trabajadores sobre la guerra civil en Francia en 1871. En Marx, Karl, Engels, Friedrich y Lenin, Vladimir. La Comuna de Paris (5-70). Madrid: Akal.

Negri, Antonio (1994). El poder constituyente. Ensayo sobre las alternativas de la modernidad. Madrid: Ensayo.

Negri, Antonio (2004). Los libros de la autonomía obrera. Antagonismo, organización, comunismo: hipótesis para la nueva política del sujeto hiperproletario global. Madrid: Akal.

Negri, Antonio (2007). Goodbye Mr. Socialism. Barcelona: Paidós. 
Negri, Antonio y Guattari, Felix (1996). Las verdades nómadas. Por nuevos espacios de libertad. Irún: Iralka.

Negri, Antonio y Hardt, Michael (2011). Commonwealth. El proyecto de una revolución del común. Madrid: Akal.

Negri, Antonio y Hardt, Michael (2019). Asamblea. Madrid: Akal.

OECD (1998). Integrating Distressed Urban Areas. Paris: OECD.

Sassen, Saskia (200o). La ciudad global: Nueva York, Londres, Tokio. Buenos Aires: Eudeba.

Sassen, Saskia (2010). Territorio, autoridad y derechos: de los ensamblajes medievales a los ensamblajes globales. Buenos Aires: Katz.

Schwab, Klaus (2016). La cuarta revolución industrial. Barcelona: Debate.

Shmelev, Stanislav y Shmeleva, Irina (2019). Multidimensional sustainability benchmarking for smart megacities. Cities, 92, 134-163. doi: 10.1016/j.cities.2019.03.015

Secchi, Bernardo (2013). La città dei ricchi e la cittá dei poveri. Roma-Bari: Laterza \& Figli.

Sennett, Richard (2018). Building and Dwelling: Ethics for the City. New York: Farrar, Straus and Giroux.

Soja, Edward W. (2008). Postmetrópolis. Estudios críticos sobre las ciudades y las regiones. Madrid: Traficantes de sueños.

Srnicek, Nick (2018). Capitalismo de plataformas. Buenos Aires: Caja Negra.

Tafuri, Manfredo (1995). Sobre el Renacimiento, Principios, ciudades, arquitectos. Madrid: Editorial Cátedra.

Tomás Fornés, Mariona y Cegarra Dueñas, Blanca (2016). Actores y modelos de gobernanza en las Smart Cities. URBS, 6(2), 47-62.

Toret, Javier, Calleja, Antonio, Marín, Óscar, Aragón, Pablo, Aguilera, Miguel, Barandiaran, Xabier E., Lumbreras, Alberto y Monterde, Arnau (2015). Tecnopolítica y 15M: La potencia de las multitudes conectadas. Barcelona: UOC.

Virilio, Paul (2006). Speed and Politics. Los Angeles: Semiotext(e).

Wacquant, Loïc (2007). Parias urbains. Ghetto, banlieues, État. Paris: La Découverte. 
Weber, Max (1987). La ciudad. Madrid: La Piqueta.

Williams, Alex (2015). Control Societies \& Platform Logic. New Formations, 84/85, 209-227. doi: 10.3898/neWf:84/85.10.2015

Zibechi, Raúl (2007). Dispersar el poder. Los movimientos sociales como poderes antiestatales. Barcelona: Virus.

Zibechi, Raúl (2012). Territorios en resistencia. Cartografía política de las periferias urbanas latinoamericanas. Málaga: Baladre-Zambra.

Žižek, Slavoj (2006). Irak. La tetera prestada. Madrid: Losada. 